\title{
A Comparative Study of Digital Terrain Data for Visibility Analysis in the Planning and Management of Scenic Resources
}

\author{
Toru Otawa \\ Faculty of Landscape Architecture, University of Idaho, Idaho 83844-2481, USA
}

\begin{abstract}
A DEM (digital elevation model) was once used to calculate viewsheds in the early days of GIS applications. The emergence of LiDAR (light detection and ranging) data which are likely to have higher spatial resolutions than traditional DEMs contributed to the improvements of calculation accuracy greatly. The objective of this study is to validate that the LiDAR data calculate and predict a viewshed better than the traditional low-resolution DEMs with $10 \mathrm{~m}$ and $30 \mathrm{~m}$ spatial resolutions. Using digital terrain data acquired for part of the Nez Perce National Forest in Idaho, calculation accuracy for viewsheds was scrutinized in depth. Four hundred and eighty four (484) observation points were selected randomly to compute viewsheds from the 1-m pixel, bare-earth LiDAR data and from the traditional $10 \mathrm{~m}$ and $30 \mathrm{~m}$ DEMs. The comparison of their RMSEs (root-mean-squared-error) values proves the newer generation of digital terrain data produces more accurate viewsheds than ones generated from the traditional DEMs. Analyses of variance and $t$-tests show the viewsheds calculated from various terrain models are statistically different. Therefore, findings from this study suggest that high-quality LiDAR data, if available, should be used for decision-making in planning for and the management of the scenic resources.
\end{abstract}

Key words: Viewshed analysis, GIS, LiDAR, digital elevation model, digital surface model.

\section{Introduction}

Visibility analysis was conceptualized and carried out by the US Forest Service (e.g., [13]) and other federal agencies (e.g., the Bureau of Land Management or BLM) in the 1960s in response to many environmental protection laws enacted during that decade (e.g., National Environmental Protection Act or NEPA of 1969). Many of these federal agencies have applied visibility analyses in a number of planning projects to help manage natural resources better. Applications of viewshed analysis included scenery management in forested lands; locating fire-lookout towers; studying visual impact of the siting of large structures such as cooling towers for a nuclear power plant; siting of utility-scale wind turbines in the form of a wind farm, to name a few.

Corresponding author: Toru Otawa, Ph.D., research fields: geo-spatial land planning and geo-design. E-mail: otawat@uidaho.edu.
Maintaining excellent scenic quality of a tourist region is of primary importance to the tourist industry, and this analytical tool has contributed to identifying critical sceneries for protection and preservation. To note, it was known that military applications existed, but they are excluded from the above list.

During the initial development period of this concept and associated exploratory methods, viewshed analysis was performed manually using the USGS (United States Geological Survey) 7.5-minutes series topographic maps (e.g., [13]). The manual method was very time-consuming and cumbersome, and the analysis results were significantly crude and inaccurate by today's standard. The introduction of mainframe and mini-computers served as a powerful incentive to move from the manual method to computer-aided visibility analysis of a viewshed [4]. The amount of time for analysis was shortened comparatively, but the results remained crude and 
rudimentary due to the very low-resolution of input data, e.g., $30 \mathrm{~m}$ DEM (digital elevation model) by USGS. The recent advancements of CPU (central processing units) did not contribute to the improvements of accuracy in visibility calculations because the resolution of terrain data remained relatively coarse, e.g., USGS 10 m DEMs until recently.

However, a new generation of terrain data has been introduced for the last few decades. The terrain data derived from LiDAR (light detection and ranging) technology maintain higher spatial resolution typically ranging from sub-meter to $3 \mathrm{~m}$ in pixel size. Although many issues remain unresolved in the terrain data obtained from LiDAR today as described in subsequent sections, it is generally safe to state that the calculation and prediction of viewsheds yield better results from the LiDAR data than from the traditional low-resolution terrain data, namely $10 \mathrm{~m}$ and $30 \mathrm{~m}$ DEMs [15]. This broader hypothesis should be tested to confirm this statement further by a parametric approach and the larger observations of the viewshed data. Due to the non-parametric method that the previous study adopted and the small sample size chosen, findings were not conclusive [15].

Anonymous researchers claim that findings from such a comparative study are apparent and that the accuracy issue has been known since the introduction of LiDAR data a few decades ago. Therefore, these researchers insist that the present study is not current. However, a review of the literature on the selected subject does not substantiate the above claim, since very few on this specific subject are identified. Additionally, significant gaps exist between professional practice and the existing knowledge within the viewshed research community. Thus, there is an urgent need to fill the gap for the betterment and advancement of scenic resource management particularly with reference to forest landscapes.

\section{Research Objectives}

Most importantly, the aim of this research is to determine if the viewsheds calculated from three resolution levels of digital terrain data (namely $30 \mathrm{~m}$, $10 \mathrm{~m}$ and $1 \mathrm{~m}$ ) are similar or different. In other words, the resolution of DEMs may largely relate to the accuracy of a computed viewshed and require further investigation and examination.

Next, an inquiry should be made with respect to the heights of observer positions as they relate to a resulting viewshed. This research also aimed at comparing two viewsheds, one calculated from the default observer height of $1 \mathrm{~m}$ and the other from a representative observation height of $1.75 \mathrm{~m}$ to understand any differences between the two viewsheds.

Lastly, with the findings from this research, it is hoped to close the gap of knowledge between practicing professionals in viewshed management and planning, and the research community engaged in advancing the knowledge of scenic resource management. Note that this objective is not meant for scrutiny in this research, but findings from it will ultimately be transferred to the professional community.

\section{Existing Knowledge on Viewshed Calculation Accuracy}

A comprehensive review of previous viewshed studies took a methodological and qualitative approach [5]. A recent study provided a comprehensive view of past and current trends in visualization research including the field of visibility calculations and viewshed analysis [14]. Previous studies of viewshed analysis were reviewed in enhancing prediction accuracy due to uncertainties in digital terrain data, for example, DEMs [15]. Therefore, this paper will not review them repetitively but rather attempt to summarize the existing literature through methodologies and approaches.

The inaccuracies of viewsheds computed from $30 \mathrm{~m}$ and $10 \mathrm{~m}$ DEMs have been recognized and therefore scrutinized by a number of researchers ever since GIS 
software became available for visibility analysis. The mainstream approach to handling the inaccuracy issue was to integrate probability theories in the viewshed calculation process. Many studies (e.g., [6-10]) used the Monte Carlo simulation or a comparable technique to manage random error in a stochastic process.

Another research direction was to blame computation errors not only on the raster data format but also on a software algorithm and on the terrain data format. The square and columnar shape of the latter to represent terrain tends to behave as an obstacle, particularly when a course resolution of DEM is used for visibility calculations. To overcome this particular limitation associated with the raster data format, some researchers (e.g., [1]) adopted a TIN (triangulated irregular network) as the data source for visibility calculations. Furthermore, viewsheds were computed from several software programs designed for visibility calculations and compared with field-observed viewsheds to determine the accuracy of viewshed prediction by each of the programs [16]. Addressing geometric issues associated with DEM, similar to Ref. [1], an improved algorithm was developed by introducing solid angle units in DEMs [2]. Causes of viewshed prediction errors are described in detail [11].

However, it appears that most of their arguments may be becoming irrelevant if a LiDAR DEM or DSM (digital surface model) is used in viewshed calculations due to their refined spatial resolution and associated RMSEs (root mean squared errors) as mentioned above. In addition, one of the underlying assumptions, i.e., no surface obstacles exist in raw DEMs, may be erroneous in most of the common landscapes.

In summary, a number of previous studies focused on causes of error in viewshed calculations and on various approaches to help minimize the error. The errors in computed viewsheds primarily originate from:

(1) inherent errors in DEMs such as the errors introduced during the data capture process;

(2) differences in data models such as DEM vs. TIN;

(3) resolution of digital and analog data if contours are captured from paper maps;

(4) software algorithms in viewshed computation;

(5) presence of surface objects such as buildings and trees.

These error arguments may be obsolete mostly due to increasingly available new data sources, namely high resolution DSMs (digital surface models) derived from advanced survey instruments such as high-end GPS receivers and LiDAR.

Early visibility studies used low resolution DEMs to compute viewsheds and assumed that no obstacles existed on the earth surface. This assumption is erroneous in most typical landscapes. An exception may include a barren landscape without any objects such as a desert and post-harvest farmlands. To sum up, the traditional arguments about accuracy may no longer be relevant to modern digital terrain data, but rather a new research agenda is emerging. This research project is an effort to address one of the emerging needs, i.e., to examine variations of viewsheds from different terrain models. The emerging agenda also includes the research needs that relate to LiDAR data capturing, although the capturing techniques are improving rapidly and the LiDAR data captured today are generally of high quality for research and application uses.

\section{Area of Study}

The area of scrutiny is located in central Idaho approximately $40 \mathrm{~km}$ northeast of Grangeville, Idaho, USA and encompasses $302.5 \mathrm{~km}^{2}$. The concerned LiDAR data were acquired to cover the entire study area (Fig. 1). This area was selected for scrutiny because the acquired elevation data were of excellent quality [3].

The area contains a variety of topographic configurations and variations. The $1 \mathrm{~m}$ DEM data 


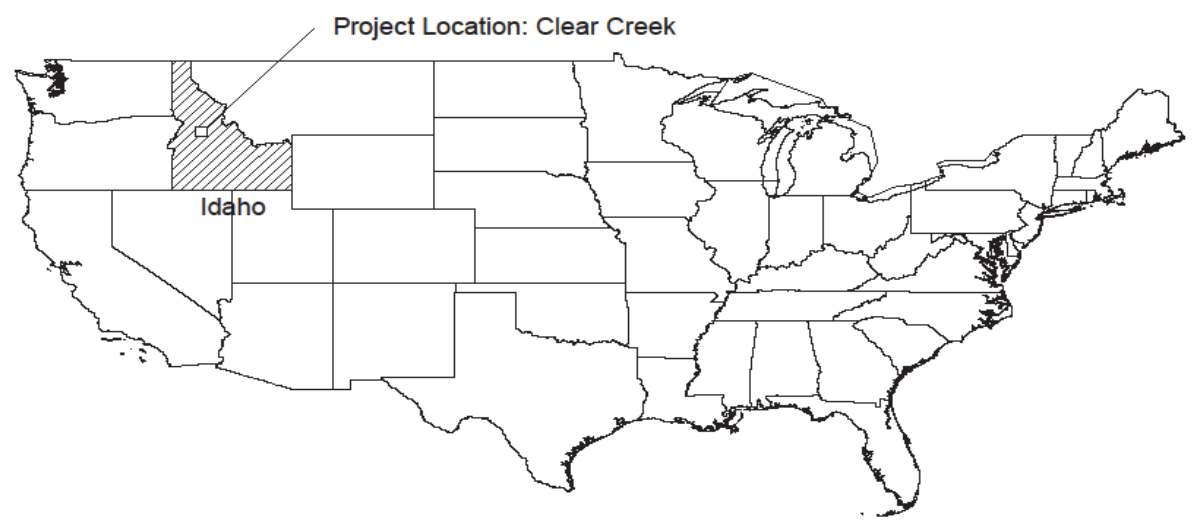

Fig. 1 Project location: Clear Creek-40 km northeast of Grangeville, Idaho, USA.

obtained from a LiDAR survey showed an average elevation of $1,308.48 \mathrm{~m}$ with the standard deviation of 251.24 for the study area selected. It is mostly covered by mature timber which is being managed by the Nez Perce National Forest, which is under the management of the US Forest Service.

\section{Data and Tools for Analysis}

In this research, three sources of digital terrain data were used for viewshed calculations and comparison. They are (a) $30 \mathrm{~m}$ DEM, (b) $10 \mathrm{~m}$ DEM and (c) $1 \mathrm{~m}$ DEM and DSM derived from LiDAR. The DSM data were left for another study, since ArcGIS could not process both DEM and DSM simultaneously in computing a viewshed. In other words, it could not set observer heights from a DEM while calculating viewsheds from a DSM layer without re-programming the viewshed software tool. Both $30 \mathrm{~m}$ and $10 \mathrm{~m}$ DEMs were obtained from the USGS NED (National Elevation Data) server and were extracted to fit the boundaries of the study area after re-projection as described below [16]. The $1 \mathrm{~m} \mathrm{LiDAR}$ data (i.e., both first-return and bare-earth) were obtained from the Forest Sciences Laboratory of the US Forest Service Rocky Mountain Research Station located in Moscow, Idaho, USA, but only the latter was used for the present study. This particular data set was acquired by one of their contractors, Earth Eye, LLC of Orlando, Florida after a number of flights for surveying by LiDAR over the study area in October 2009 [3]. This data set was acquired for the "Clear Creek LiDAR Project" to meet the need of US Forest Service research missions. The final calibration of the combined DSM yielded a root-mean-squared error of (z) or RMSE $z$ of 0.044 which represents the geospatial data of very high quality [3]. The RMSE value of traditional LiDAR data ranges from 0.1 to 0.3 generally.

The NED DEMs were assigned the GCS (geographic coordinate system) initially by USGS as the geo-referencing system. After downloading the data layers, they were re-projected to the UTM (Universal Transverse Mercator) projection (in North American Datum or NAD of 1983, Zone 11 N) which was the common thread for all digital terrain data used in this study. The same projection was assigned to the observer position data which will be described later.

Table 1 shows the RMSE values of all DEMs by resolution levels used in this study. The RMSE values for each USGS Quadrangles covering the entire study area were obtained from the attribute tables of index layers named dsindex_xx (for $30 \mathrm{~m}$ resolution) and dsined (for $10 \mathrm{~m}$ resolution). These values are within the range of the targets for data production [12]. The RMSE value of 0.044 for the $1 \mathrm{~m}$ DEM has already been shown.

All viewsheds were calculated using the viewshed analysis tool in $\operatorname{ArcGIS}^{\circledR}$ Version 10.x without the earth curvature option on. A Model Builder model was designed for iterating viewshed calculations (Fig. 2) 
Table 1 Comparison of RMSE values for three levels of DEM resolution.

\begin{tabular}{llllllc}
\hline & \multicolumn{5}{c}{ DEM Resolution } \\
\cline { 2 - 6 } & \multicolumn{7}{c}{ R0 m } & \multicolumn{1}{c}{$10 \mathrm{~m}$} & $1 \mathrm{~m}$ \\
\hline Quadrangle & RMSE (X, Y) & RMSE (Z) & RMSE (X,Y) & RMSE (Z) & RMSE (X,Y) & RMSE (Z) \\
Big Cedar & 1 & 12 & 1 & 2 & 0.1 & 0.044 \\
Corral Hill & 1 & 9 & 1 & 2 & 0.1 & 0.044 \\
Lodge Point & 1 & 6 & 1 & 2 & 0.1 & 0.044 \\
Pilot Knob & 1 & 4 & 1 & 2 & 0.1 & 0.044 \\
\hline
\end{tabular}

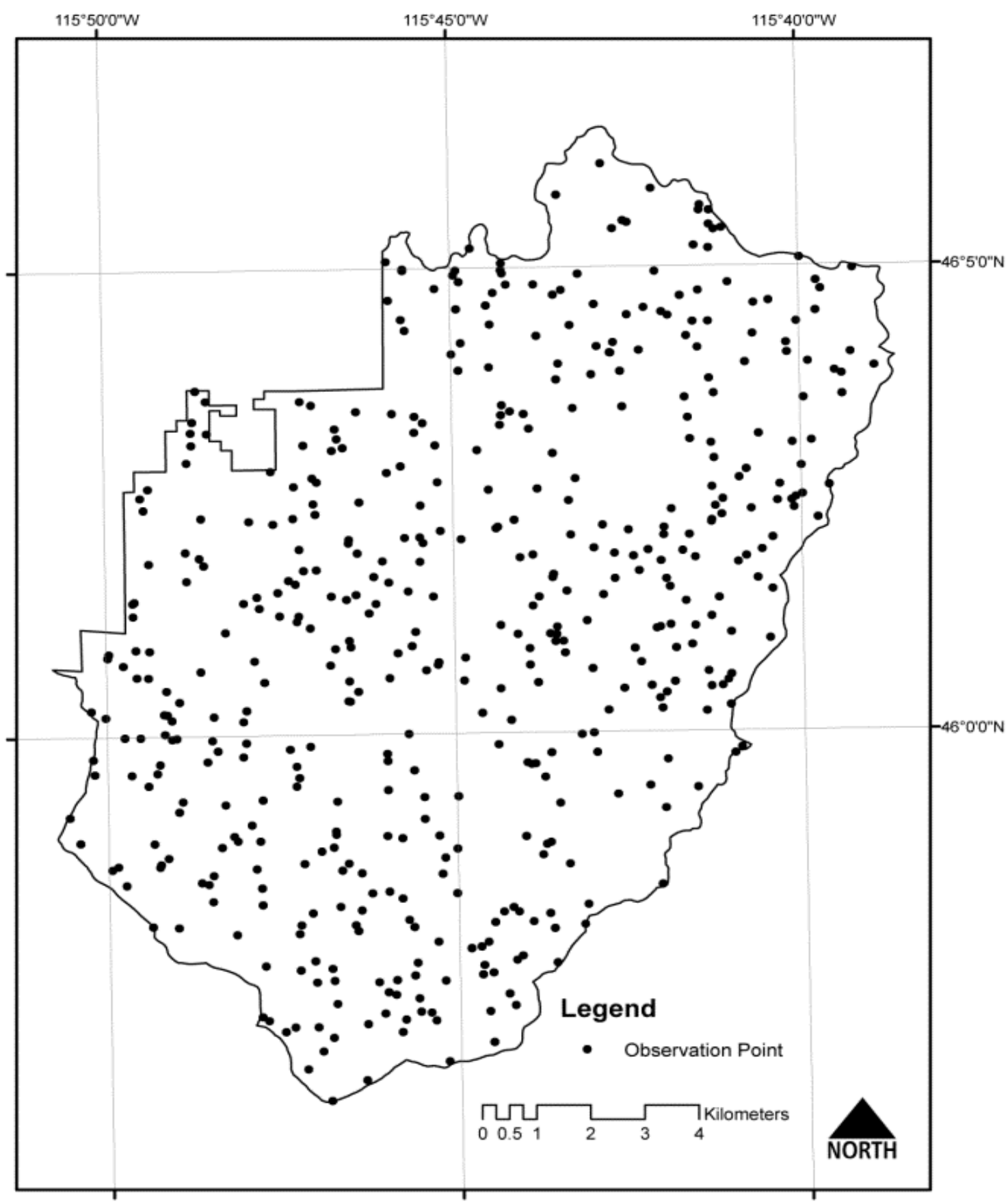

Fig. 2 Randomly-selected observation points with boundaries for study area. 
and a Visual Basic ${ }^{\circledR}$ macro for Microsoft Excel ${ }^{\circledR}$ was developed to tabulate the percentages of visible and invisible areas on a viewshed. The $G *$ Power Version 2 and $\mathrm{JMP}^{\circledR}$ software programs were used to determine the appropriate sample sizes in the subsequent statistical analyses, where two other programs were used for statistical analyses, namely SYSTAT $^{\circledR}$ Version 12 and "R" Version 2.15. The former was used primarily to verify the results from a $t$-test. The JMP software was not acquired until a later stage of data analysis to determine the sample size for visibility calculations.

\section{Methods}

USGS DEM tiles of both $30 \mathrm{~m}$ and $10 \mathrm{~m}$ resolutions were clipped into the study area boundaries which matched with the LiDAR data coverage. Furthermore, their grid-cell resolution was refined to $1 \mathrm{~m}$ using the RESAMPLE tool in ArcToolbox for the purpose of statistical analysis, and this tool uses the nearest neighbor assignment algorithm by default for re-sampling geo-spatial data within a $30 \mathrm{~m}$ and $10 \mathrm{~m}$ grid-cell. Therefore, all re-gridded cells received the same elevation value as the original grid-cell. For instance, a grid-cell from the $10 \mathrm{~m}$ DEM was split into 100 grid-cells (i.e., 10 by 10) and each received the elevation value from the original grid-cell. Consequently, all three types of DEMs were structured for the same number of grid-cells to be used in analysis and their geographic coordinates were aligned exactly (i.e., 900 1-m grid-cells per original grid-cell in a $30 \mathrm{~m}$ DEM and 100 1-m grid-cells in a $10 \mathrm{~m}$ DEM). To note, there was a slight variation in the total number of grid-cells due to geo-spatial truncation on the borders of the study area during the resampling process, but a difference of a few grid-cells will make very little difference statistically in this particular case. The final grid-cell resolution used in calculations was 15,551 by 19,424 , a total of $302,043,200$. Given the pixel size of $1 \mathrm{~m}$ by $1 \mathrm{~m}$, this area covers approximately $302 \mathrm{sq}$. $\mathrm{km}$. as mentioned earlier.

Observation points, another data layer required for visibility analysis, were generated randomly using the Create Random Points tool in the "Data Management Tools" of ArcToolbox. As an initial estimate, the power analysis tool using the $G$ *Power software revealed 484 points to represent this particular topographic surface statistically for a comparative analysis of $30 \mathrm{~m}$ and $10 \mathrm{~m}$ DEMs, given the mean and standard deviation differences of 0.060 and 0.365 respectively to achieve the effective power of 0.95 (i.e., calculated from a paired $t$-test). These observation points generated by the above tool are shown in Fig. 2.

To iterate, 484 observations of visible and invisible percentages were used for $t$-tests in the present study which, in turn, achieved more than the power of 0.99 . This particular number of observation points easily exceeded the minimum number of samples required for this study. Using the $\mathrm{JMP}^{\odot}$ software, which was obtained at a later stage of analysis, another pilot $t$-test for power calculation (@0.05, two-sided, mean and standard deviation differences of -0.9353911, 2.82691 respectively) indicated only 121 observations were necessary to achieve the power of 0.95 .

Using each of the DEMs and the random observation points above, an iterative model was created in Model Builder for viewshed computations as shown in Fig. 3.

The model used the record ID of each observation point in the "CC_Obs" point feature layer as shown in the "Iterate Row Selection" steps in Fig. 3 to generate a binary viewshed layer. As the result, 484 viewshed layers were created for each of the DEM resolutions.

The model was executed for each of the DEM data and required approximately 14 consecutive days in computing 484 binary viewsheds for each of the DEMs. In total, eight comprehensive sets of viewshed data were generated for each of the 484 observation points totalling 3,872 binary viewsheds. It required approximately 120 days of continuous viewshed 


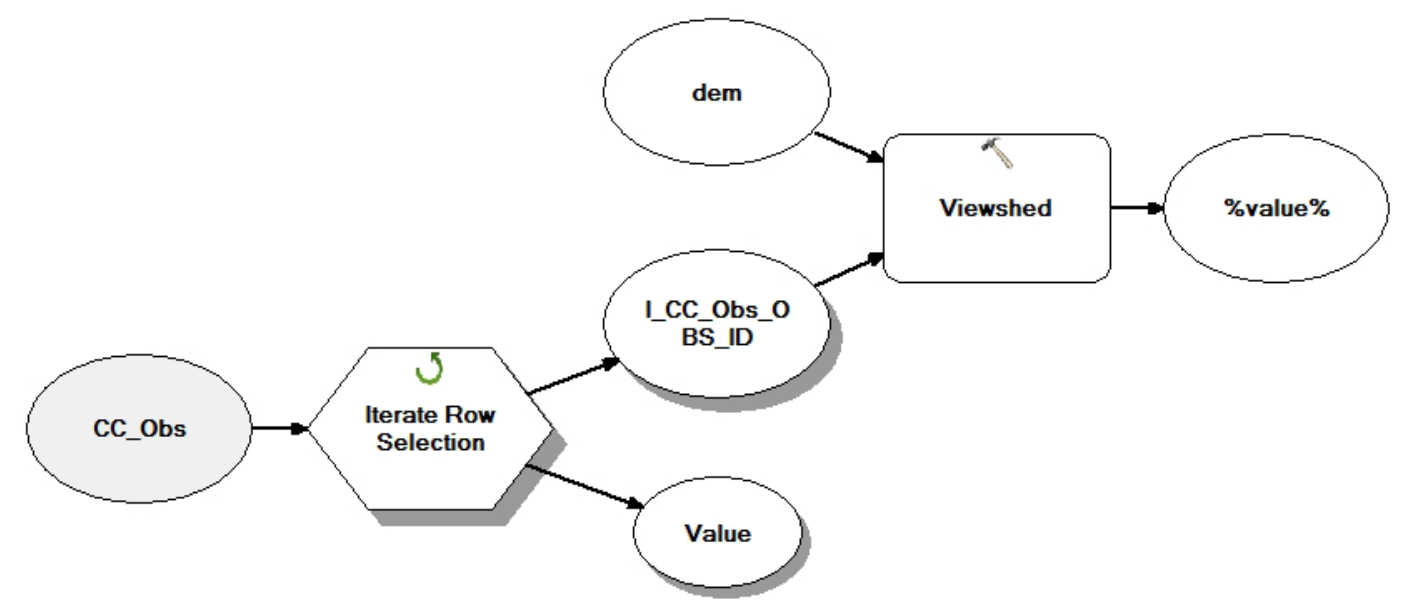

Fig. 3 Iterative viewshed calculation model in ArcGIS Model Builder.

calculations on an Intel Xeon ${ }^{\circledR}$ workstation.

Once all calculations were complete, the percentages of both visible and invisible areas were calculated from the tabular data of each viewshed data layer. Four hundred and eighty four (484) records were included in the tabulated column per each viewshed and were subsequently exported from DBF files in the ArcGIS ${ }^{\circledR}$ GRID format to a series of records in an MS Excel® file by creating a macro in Visual Basic ${ }^{\circledR}$. The Excel files contained three columns, Record (or Feature) ID, percentage of visible grid-cells, and percentage of invisible grid-cells within the study area. Each set of 484 records was subsequently used to examine normality of the visible vs. invisible ratio data and this phase included the transformation of the data afterwards.

Then, an " $\mathrm{R}$ " code was written to examine the effects of DEM resolutions in viewshed calculations (Fig. 4). Once the visibility percent data were transformed using the Box-Cox method which resulted in the best fit, a normality assumption was checked with the Bartlett test by examining the homogeneity of variance. In addition, the results of transformation were plotted to help validate the assumption. Finally, an ANOVA (analysis of variance) was performed.

Viewsheds calculated from three resolution levels of DEMs (i.e., $1 \mathrm{~m}, 10 \mathrm{~m}$ and $30 \mathrm{~m}$ ) were compared first. Next, the effect of observer height was examined. A few simple $t$-tests were performed for a pair of observation heights and LiDAR data types, (e.g., viewsheds calculated from $1 \mathrm{~m}$ and $1.75 \mathrm{~m}$ observer heights) to prove or disprove a hypothesis that varied data types and observer heights generate different viewsheds. In ArcGIS, the observer height is assigned as a unitless value by default, but the terrain data are in the UTM projection of which unit is metric. Thus, this particular software treats the default observer height as $1 \mathrm{~m}$. In calculating viewsheds from the $1.75 \mathrm{~m}$ observer height, the value in the field named "OFFSETA" was changed to 1.75 in the attribute table of the observer position layer.

\section{Results and Discussions}

\subsection{Accuracy of DEMs Used}

From the comparison of RMSEs in Table 1, it is safe to state that the $1 \mathrm{~m}$ DEM is more accurate than the $10 \mathrm{~m}$ DEM which is also better than the $30 \mathrm{~m}$ DEM. Considering all other parameters are identical in visibility calculations (e.g., observer height and software algorithm), the viewsheds calculated from the $1 \mathrm{~m} \mathrm{DEM}$ are more accurate than ones from the 10 $\mathrm{m}$ DEM. The same is true for viewshed accuracies from the $10 \mathrm{~m}$ and $30 \mathrm{~m}$ DEMs. 


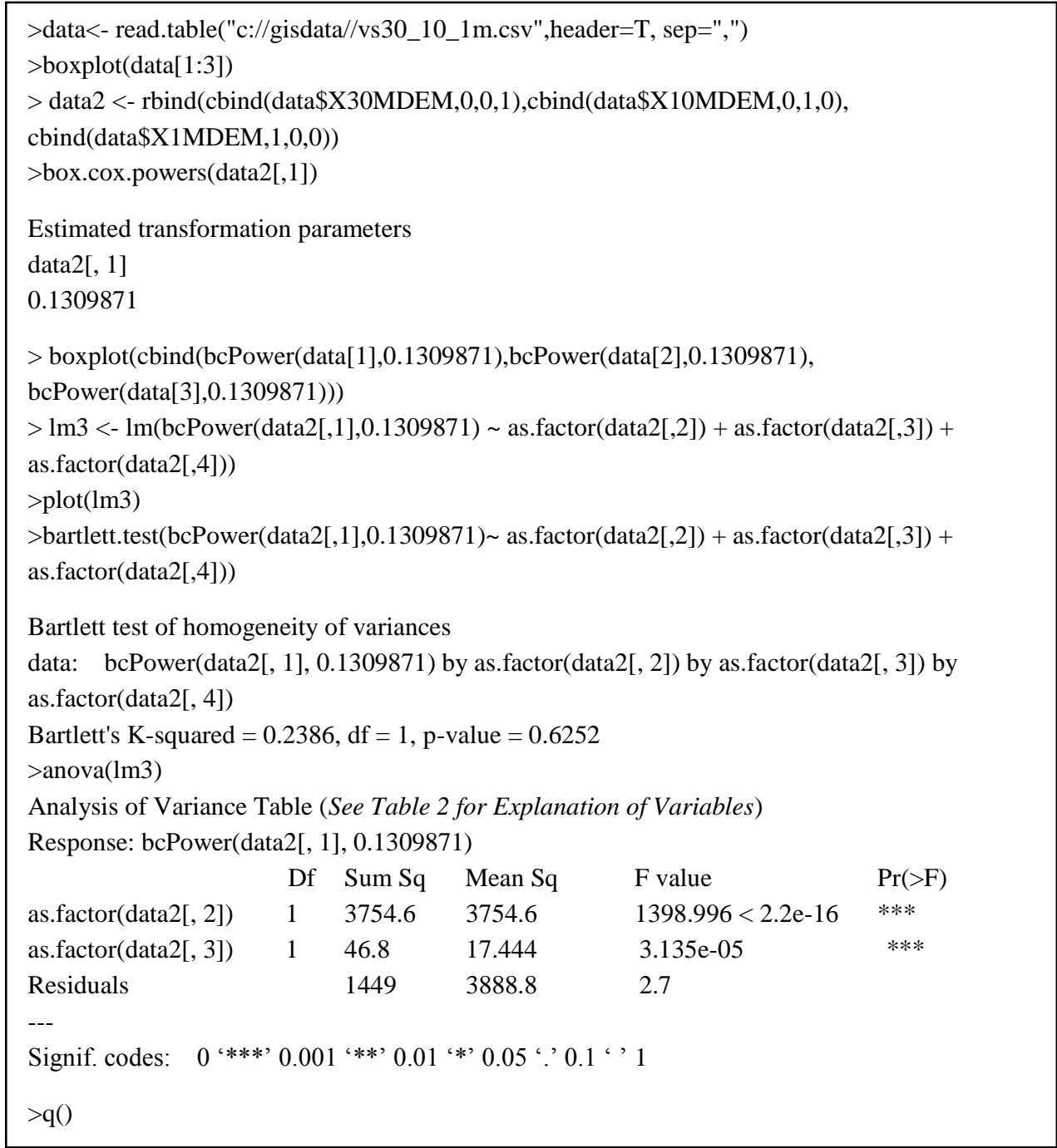

Fig. 4 "R" code for ANOVA for comparison of viewsheds from three levels of DEM resolution.

Table 2 ANOVA table for comparison of viewsheds from three levels of DEM resolution.

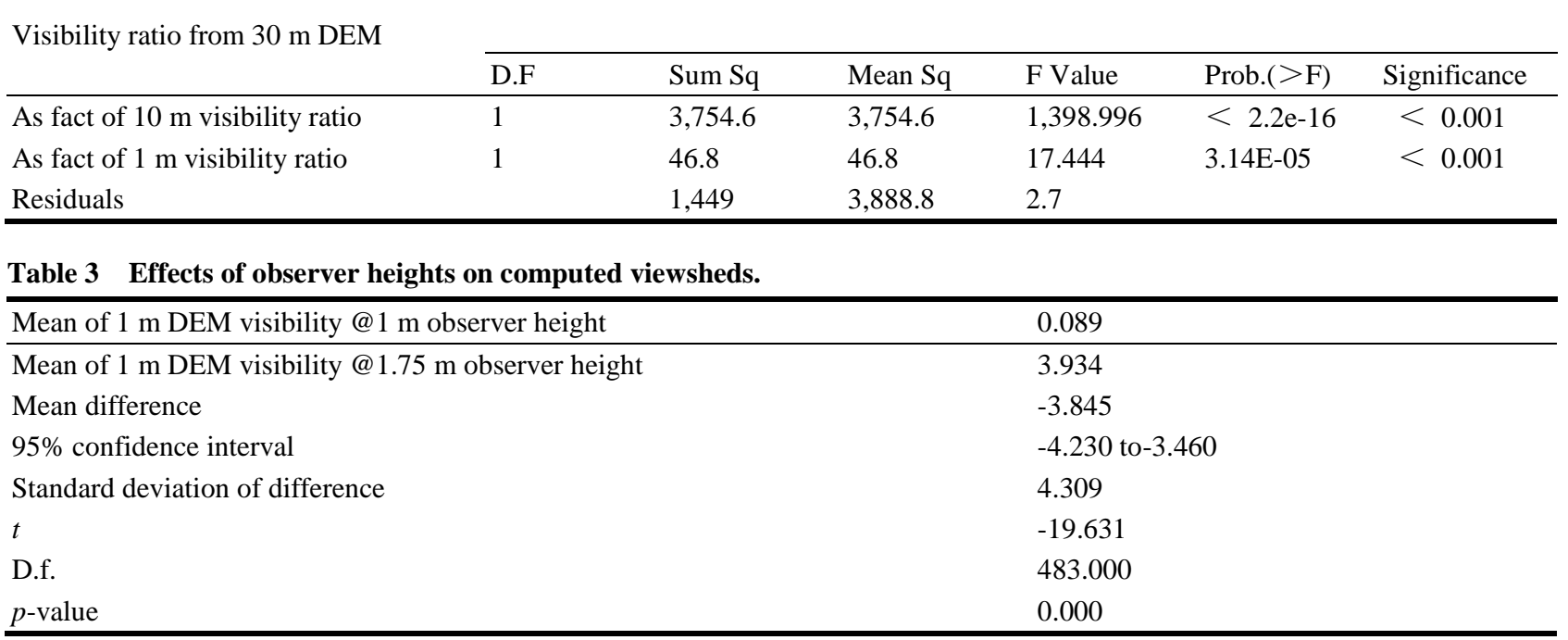




\subsection{Effect of Different DEM Resolution on Resulting} Viewsheds

The final results from the analysis of variance calculations are shown in Table 2.

The probabilities in all analyses suggest that the null hypothesis of no difference should be rejected. From this ANOVA, it is evident that calculations from three varied resolutions of DEMs yielded different viewsheds. It is also safe to state that viewsheds from $1 \mathrm{~m}$ DEMs resulted in better and more accurate viewsheds than those calculated from $10 \mathrm{~m}$ and $30 \mathrm{~m}$ DEMs, referring to the RMSE values in Table 1. However, $1 \mathrm{~m}$ DEMs do not reflect the heights of any objects on the surface of the earth; therefore, it is far from being realistic, and in this sense the 1-m resolution, bare-earth data may be an erroneous representation of the landscape, particularly where surface objects exist such as forested land or urban and suburban areas.

\subsection{Effect of Different Observer Heights on Resulting} Viewsheds

In this section, the viewsheds from $1 \mathrm{~m}$ observer height (i.e., default height) were compared with ones from $1.75 \mathrm{~m}$, with the null hypothesis being "no difference". In this particular test, viewsheds were calculated only from the 1-m resolution DEM. Another $t$-test shows the $p$-value of 0.000 (Table 3). Thus, it is safe to reject the null hypothesis, and one can state that the heights of observers make a difference in the way viewsheds are calculated even if there is a mere difference of $0.75 \mathrm{~m}$.

In summary, it was found that even a height difference of $0.75 \mathrm{~m}$ would yield different viewsheds when a large region is scrutinized.

\section{Conclusions}

This research addressed the issues in viewshed calculations and potential errors due to the types of terrain data and resolution, as well as the heights of observation. Three varied pixel resolutions of DEMs were compared statistically and it was found that viewsheds computed from each DEM resolution distinctly vary on the whole. Combined with findings from our previous pilot study (i.e., viewsheds may be computed differently depending on the level of DEM resolution) [15], one may conclude that viewsheds from $1 \mathrm{~m}$ DEMs result in a better representation and depiction of barren terrain.

However, as mentioned previously, such a barren landscape is atypical, particularly in a forest setting. Logic dictates surface objects should be taken into consideration during visibility calculations. In this regard, traditional low-resolution DEMs may no longer be suited to viewshed analysis. This is particularly true where a large area is in scrutiny.

Such an area is most likely to include a diverse form of landscape with numerous surface objects which could act as visual barriers, as well as flat surfaces and barren lands. Thus, DEMs may not simulate realistic viewsheds even if a DEM has a high pixel resolution. Conversely, DEMs of high resolution and quality may be used where few surface objects exist such as agricultural fields with few grown crops or a desert within a foreground zone.

Unfortunately, higher-resolution data require more computing power to process. Although visibility calculation has improved dramatically in recent years, it still requires the fast processing of terrain data in the high-performance computing environment (e.g., a supercomputer) due to the algorithm inherent in the viewshed calculation software. A new approach (e.g., better algorithm such as one shown below) would be needed to calculate visibility with least intensive computing. Furthermore, this research revealed that the differences in viewing heights will make much difference in the resulting viewshed. Thus, setting an appropriate observer height prior to visibility calculations is also critical in calculating and predicting an accurate viewshed. That height is commonly determined by the objectives and needs of 
a study.

As of this writing, an increasing number of LiDAR data are being generated by various organizations such as federal and state government entities that are responsible for land management and for other land-related missions. This study suggests that wherever such data are available, a viewshed analyst should make a maximum use of the high-resolution terrain data.

However, such data are not always available for various viewshed studies. Sound and reasonable viewshed predictions might be possible if high quality DSM data are made available in the proximity of observer positions and the present visibility calculation software (e.g., a tool in $\operatorname{ArcGIS}^{\circledR}$ ) is modified to accommodate DSMs as an input data source [15]. As of this writing, it is not possible without substantial modifications to the software to set an observation point under the tree canopy, if a DSM is used.

Additionally, such data do not have to cover middle- and background zones since errors in vertical heights in these zones will have little effect on predicting viewsheds in them. Combining a DSM in the foreground zone with lower-resolution DEMs in the middle- and background zones might be a good approach to save project costs. A follow-up study is necessary to verify the effectiveness of this approach. To take advantage of this method of combining data models, clearly defining a path that an observer plans to travel will lead to sound viewshed calculations and may result in cost savings in a project for visibility analysis. Accordingly, an analyst will be able to limit the area for collecting DSM data to reduce the costs associated with a viewshed project.

A subsequent research project may be carried out to substantiate such a presumption by collecting field data and comparing the results of viewshed calculations from the hybrid data sources as described above. In addition, many issues still exist in collecting accurate LiDAR data such as the dispersion of data points by reflection of light sources. Various disciplines may be required to participate in researching such complex issues for proper solutions and improvements. Other research of importance may include subjects such as:

(1) examining the sensitivity of LiDAR data in addressing partial occlusion-gaps in tree canopies and the transparency of individual trees, and

(2) scrutinizing how the high resolution DSM data can help improve alternative approaches to viewshed analyses such as an isovist and three-dimensional visual modelling. The isovist is volumetric space visible from a point within the space.

It is hoped that the ever-increasing power of computers together with the improvements in data resolution and accuracy will help predict and yield highly accurate viewsheds for the betterment of scenic resource management.

\section{Acknowledgments}

Many thanks go to the Forest Sciences Laboratory of the US Forest Service Rocky Mountain Research Station located in Moscow, Idaho, USA for providing this researcher with a set of LiDAR data that was collected for their Clear Creek LiDAR project in the Nez Perce National Forest. Ed Flathers, a graduate student at the Statistical Consulting Center at the University of Idaho, assisted the researcher in statistical analyses such as writing an " $R$ " code for data transformation.

\section{References}

[1] Dean, D. J. 1997. "Improving the Accuracy of Forest Viewsheds Using Triangulated Networks and the Visual Permeability Method." Can. J. of For. Res. 27 (7): 969-77. doi:10.1139/x97-062.

[2] Domingo-Santos, J. M., Fernandez de Villara, R., Rapp-Arraras, I., and Corral-Pazos de Provens, E. 2011. "The Visual Exposure in Forest and Rural Landscapes: An Algorithm and a GIS Tool." Landscape Urban Plan 101 (1): 52-8.

[3] Eartheye. 2009. Nez Perce National Forest, Clear Creek LiDAR Project: Final Report. Orlando, Florida. 
[4] Elsner, G. H. 1979. "Computers and the Landscape." In Our National Landscape-A Conference on Applied Techniques for Analysis and Management of the Visual Resource. General Technical Report PSW-49. Berkeley, California: US Forest Service, Pacific Southwest Forest and Range Experiment Station, 88-92.

[5] Ervin, S., and Steinitz, C. 2003. "Landscape Visibility Computation: Necessary, but not Sufficient." Environ. Plann. B 30 (5):757-66.

[6] Fisher, P. F. 1991. "First Experiments in Viewshed Uncertainty: The Accuracy of the Viewshed Area." Photogramm. Eng. Rem. S. 57 (10): 1321-7.

[7] Fisher, P. F. 1992. "First Experiments in Viewshed Uncertainty: Simulating Fuzzy Viewsheds." Photogramm. Eng. Rem. S. 58 (3): 345-52.

[8] Fisher, P. F. 1993. "Algorithm and Implementation Uncertainty in Viewshed Analysis." Int. J. Geogr. Inf. Syst. 7 (4): 331-47. doi:10.1080/02693799308901965.

[9] Fisher, P. F. 1995. "An Exploration of Probable Viewsheds in Landscape Planning." Environ. Plann. B 22 (5): 527-46.

[10] Fisher, P. F. 1998. "Improved Modeling of Elevation Error with Geostatistics." GeoInformatica 2 (3): 215-33.

[11] Fisher, P. F., and Tate, N. J. 2006. "Causes and Consequences of Error in Digital Elevation Models." $\begin{array}{llll}\text { Prog. } \quad \text { Phys. } \quad \text { Geog. } 30 & \text { (4): } \quad 467-89 .\end{array}$ doi:10.1191/0309133306pp492ra.

[12] Gesch, D. B. 2007. "The National Elevation Dataset." In Digital Elevation Model Technologies and Applications - The DEM User's Manual, 99-118.

[13] Litton, R. B. 1968. Forest Landscape Description and Inventory: A Basis for Land Planning and Design. Berkeley, California: US Forest Service, Pacific Southwest Forest and Range Experiment Station.

[14] Nijhuis, S., van Lammeren, R., and van der Hoeven, F., eds. 2011. Exploring the Visual Landscape: Advances in Physiognomic Landscape Research in the Netherlands. Research in Urbanism Series. Amsterdam: IOS Press.

[15] Otawa, T. 2010. "An Exploratory Study of GIS-Aided Visibility Analysis: Implications for Landscape Planning." In Landscape Legac-Proceedings of the Council of Educators in Landscape Architecture Conference, 205.1-205.14.

[16] Riggs, P. D., and Dean, J. D. 2007. “An Investigation into the Causes of Errors and Inconsistencies in Predicted Viewsheds." Trans. GIS 11 (2): 175-96.

[17] US Geological Survey. 2003. "NED Release Notes." Accessed $\quad$ February 28, 2008 . ftp://edcftp.cr.usgs.gov/pub/data/ned/documents/NED_Re lease_Notes_Dec03.pdf. 